members of litter 7 are dubious. It would be of great interest to know whether the susceptibility of the animals to increased $g$ varies with the age at which spinning begins or the weight already attained at this time. Since rats of the same species reach a comparable weight at a comparable age, the figures so far obtained are totally inadequate for distinguishing between these two possibilities. It is relevant at this point to recall Wunder's observation" that "the larger [fruit fly] larvæ experienced a more drastic reduction in growth-rate than the smaller ones".

From the results shown in Fig. 1, it is apparent that the amount of food taken to produce an equiva. lent increase in weight (in any event in the early stages) in the spun animals is much greater than that required by their controls. A more detailed investigation of this phenomenon is at present being planned.

I thank Prof. R. J. Harrison, Prof. A. J. E. Cave and Dr. C. R. B. Joyce for their advice and help.

Anatomy Department, F. L. D. SteeL *

London Hospital Medical College.

- Present address: Anatcmy Department, St.Bartholomew's Hospital Medical College, Charterhouse Square, London, E.C.1.

${ }^{1}$ Rashevsky, N., Mathematical Biophysics (Univ. Chicago Press, 1948). Thompson, D'A. W., On Growth and Form (Camb. Univ. Press, 1942).

${ }^{2}$ Matthews, B. H. C., J. Physiol., 122, $31 P$ (1953).

s wunder, C. C., Proc. Soc. Exp. Biol. and Med., 88, 544 (1955).

'Edwards, Betty F., and Gray, S. W., J. Cell. and Comp. Physiol., 48, 405 (1956). Gray, S. W., and Edwards, Jetty F., ibid., 46, 97 (1955).

${ }^{5}$ Smith, A. H.. Winget, C. M., and Kelley, C. F., Growth, 23,97 (1959). Kelly, C. F., Smith, A. H., and Winget, C.'M., Ann. Progr. Rep. (No. 2) Off. of Naval Res. Proj. NR., 102 (1957).

- Steel, F. L. D., Proc. Anat. Soc. (1959); J. Anat. (Lond.), 94, 284 (1960).

'Wunder, C. C., Proc. Iowa Acad. Sci., 67, 488 (1960).

"Briney, R. B., and Wunder, C. C., Proc. Jowa Acad. Sci., 67, 495 (1960).

- Wunder, C. C., Herrin, W. F., and Cogswell, S., Proc. First Nat. Biophysics Conf., 639 (Yale Univ. Press, 1959).

${ }^{10}$ Wunder, C. C., Crawford, C. R., and Herrin, W, F., Iroc. Soc. Exp. Biol. and Med., 104, 749 (1960).

in Wunder, C. C., Herrin, W. F., and Crawford, C. R., Growth, 23, 348 (1959).

${ }^{12}$ Wunder, C. C., Briney, S. R., Kral, M., and Skaugstad, C., Nature, 188, $151(1960)$.

\section{Measurement of the Surface Area of the Human Body}

In the study of heat exchanges between the human body and its environment, physiologists in the past have been interested to know the area of the surface of the experimental subject, as this quantity appears in the equations concerning convection, radiation and evaporation. In the past, surface areas were determined by covering the surface of the human subject with patches of paper and then measuring the area of all the patches after they had been stripped off the subject. Such a method is very tedious; and an approximate equation relating surface area to the height and the weight of the subject was evolved. 'This equation is admittedly approximate and it cannot be maintained that it will be satisfactory for all ethnic types.

In the study of heat problems encountered by miners working at great depths in the South African gold mines (undertaken by the Applied Physiology Research Laboratory of the Transvaal and Orange Free State Chamber of Mines which sponsored it), it was considered that it should be possible to measure the surface areas of large numbers of mon, and $a$ physical method for achieving this object has been devised.
The method actually measures the radiation surface of the subject by the reverse method of measuring his absorbing surface when that surface has been made 95 per cent absorbant to visible light by means of a pigment. A scaled-down model of the apparatus has been constructed, and the results of the experimonts indicate that an apparatus made twice the size of the present experimental apparatus will measure the radiation surface of adult subjects with an error of not more than I per cent.

In the present experimental apparatus an integrating cube, $6 \mathrm{ft}$. on an edge, and with its corners closed by means of equilateral triangles $3 \frac{1}{2} \mathrm{ft}$. on an edge, is filled with a flux of light from eight electric lamps set, one in the centre of each triangle, and suitably sereened to produce a diffuse illumination. Experiment shows that the centre $3 \frac{1}{2} \mathrm{ft}$. cube of space within the integrating cube has a uniform light flux (variation less than 1 per cent). In one face of the integrating cube there is a frosted glass window and this window has a brightness which is directly proportional to the light flux inside the cube. A photometric bench is mounted opposite the window in the cube and at the end of the bench there is a second frosted glass window, the same size as that in the cube, but illuminated by the light from a comparison lamp which runs on a carriage on the photometer bench. The comparison lamp and the eight illuminating lamps inside the cube are all in series, so that small changes in the voltage of the supply do not affect the photometric measurements.

By means of suitable photometric arrangements, the brightness of the window at the end of the bench can be compared with that of the window in the eube and the comparison lamp can be adjusted until the two brightnesses are equal. When an object with black surface is then introduced into the cube the brightness of the window is decreased and it is possible to measure this diminution with an accuracy which is better than 1 per cent. The apparatus is calibrated by introducing objects with known surface areas and equally black surfaces, and constructing a calibration graph.

It has been found possible with the present apparatus to measure surfaces of up to $15,000 \mathrm{sq}$. cm., and experiments with two blackened disks hanging face to face at different distances have shown that what is being measured is the true radiation area of the objects being introduced. This is, of course, of considerable value to the physiologist, for the radiation area of a subject varies with his working position and this variable value can now be determined with rapidity and accuracy. Measurements on a conventionalized model of a human being have shown that a human subject in the spread-eagle position presents the largest radiation area that can be presented, and that this area is approximately 95 per cent of the true geometrical area, so that where the true geometrical area is required it can be determined.

Further work is in progress to bring the integrating cube up to $10 \mathrm{ft}$. and to make the measurements on adult human subjects, sprayed with a black dye to produce 95 per cent absorption, so that a final check of the equipment can be made and, in particular, the ratio of maximum radiation area to true geometrical area may be more precisely determined.

$$
\text { E. C. HALLIDAY }
$$

T. J. Hugo

National Physical Research Laboratory, Council for Scientific and Industrial Research, Pretoria, South Africa. 